\title{
LOS RESORTES DEL PODER EN LA NAVARRA BAJOMEDIEVAL (SIGLOS XII-XV)
}

\author{
ELOÍSA RAMÍREZ VAQUERO \\ Universidad Pública de Navarra
}

\begin{abstract}
SUMARIO
1. Las bases del poder real.- 2. Champañeses y capetos: las bases de una nueva monarquia.- 3. Sistematización financiera del territorio de la monarquia. - 4. El esplendor de los Evreux.- 5. Los reajustes de Carlos III.6. El triunfo de la fiscalidad de Estado.
\end{abstract}

El ejercicio del poder, en particular el poder soberano, y su progresiva definición, es un elemento esencial a la hora de analizar la formación y configuración de los estados modernos. Este punto de vista se halla íntimamente relacionado con la idea de que la génesis de estos "estados" consiste en un largo proceso que tiene lugar, con todos los matices pertinentes para cada caso concreto, en los siglos bajomedievales. Cabe considerar, en esta línea, que el complicado proceso de ensamblaje de los espacios occidentales ha adquirido para el siglo XIII un balance más o menos consolidado, y que la tarea que se sitúa en el horizonte consiste, a partir de entonces, en el perfeccionamiento de los resortes del poder y la vertebración de unos cuadros de gestión eficaces, que permitan a las monarquías alcanzar de manera efectiva los más profundos confines de sus contornos soberanos. Tales aspiraciones, lógicamente, llegarán a plasmarse con desiguales resultados, y en diferentes tramos cronológicos, pero representan una constante de la plenitud medieval. 
Navarra, que en el siglo XIII recibe en el trono a una nueva dinastía de origen francés, se sumerge de lleno entonces en un proceso de actualización y modernización que ya había sido iniciado por los últimos monarcas de la dinastía propiamente navarra; la instalación de la casa de Champaña aceleró el desarrollo de unos mecanismos de gobierno y gestión de la monarquía que de otro modo se hubieran configurado con mayores vacilaciones'. El análisis que aquí se presenta tiene por objeto, por tanto, recorrer este proceso de forma global, en un intento de síntesis o balance del estado de la cuestión, partiendo necesaria, aunque brevemente, de las primeras pautas reorganizativas, previas a la llegada de la casa de Champaña. En este sentido, no cabría plantear una visión de conjunto como la que aquí se pretende sin la existencia de monografías y otros análisis puntuales centrados en aspectos más precisos -en el tiempo, el espacio o la temática-, relacionados con el ejercicio del poder en sus diversas manifestaciones ${ }^{2}$ en los siglos bajomedievales navarros.

\section{LAS BASES DEL PODER REAL}

La monarquía navarra había inaugurado el siglo XIII después de un complejo período, de algo más de medio siglo de duración, durante el cual había estado en entredicho su propia legitimidad; el linaje del Restaurador se había visto en la necesidad de acometer un vasto proceso, no sólo de supervivencia entre los otros dos grandes reinos peninsulares -Aragón y

\footnotetext{
'Conviene tener en cuenta que la propia realeza capeta, en la que se intsertan los champañeses, apenas empezaba entonces, con Felipe II Augusto, a esbozar un auténtico cuadro de gestión del poder regio, y se hallaba, por tanto, en pleno proceso de renovación.

2Para el siglo XIII, destacan el estudio de R. García Arancón, Teobaldo II de Navarra. 1253-1270. Gobierno de la monarquía y recursos financieros, Pamplona, 1985; el de A. J. MARTín DUQUe y E. RAMíREZ VAQUeRo, El reino de Navarra (1217-1350), en "Historia de España fund. por R, MENÉNDEZ PIDAL" (dir. J. M. JOVER), Vol. XIII, Espasa-Calpe, Madrid, 1990, pp. 4-89. Para el siglo XIV resulta imprescindible el trabajo de J. ZABALO ZABALEGUI, La administración del reino en el siglo XIV. Pamplona, 1973, que ha sido, sin duda, la base de la mayor parte de las investigaciones al respecto, y el punto de partida de nuevas perspectivas. El siglo XV, más escaso en monografías de este tipo, ha sido estudiado, sobre todo, en sus aspectos financieros, especialmente los relacionados con el poder regio; en ese sentido cabe citar E. RAMÍREZ VAQUERO, The Royal Treasury of Navarre, a theoretical outline (1250-1450). "State Finance: The European Experience (International Conference)". University of Essex, Colchester, 1995 (Publ. Internet). Una sintesis reciente la monarquía navarra bajomedieval corresponde a B. LEROY, Le royaume de Navarre. Les hommes et le pouvoir. VIIle-XVe siècles, Biarritz, 1995. Otros trabajos más específicos serán citados en cada caso.
} 
Castilla-, sino, sobre todo, de recuperación de aquella legitimidad, y de reorganización de sus espacios soberanos ${ }^{3}$, que habían ido acompañadas de un ulterior reforzamiento de los resortes del poder. El proceso cuenta al menos con dos aspectos que interesa resaltar aquí; el primero se refiere a la propia esencia de la realeza y a un programa completo de redefinición de la monarquía: quedará descartada la anterior imbricación de la corona pamplonesa en las relaciones personales y los lazos de dependencia, según se desprendía de la definición del monarca como "rey de pamploneses", o del reino como "de Pamplona". Sería Sancho el Sabio quien diera un vuelco radical a la intitulación regia, dotándola de un carácter territorial, el que comporta el título de "rey de Navarra"4 aplicación efectiva de esa nueva noción, haciendo llegar el poder soberano hasta el último confín del reino, ese espacio que se quiere definir como "reino de Navarra, a través de una renovación de los cuadros de mando, de la fundación de una serie de enclaves privilegiados de realengo, y a través, también, de una reorganización completa de la gestión del patrimonio regio 5 .

La idea de que un territorio bien articulado, ordenado y debidamente cohesionado es un espacio más aprehensible, que responde a los estímulos del poder organizador, no se halla muy lejos del esquema de reajustes financieros de Sancho el Sabio y de su profundo impulso al proceso urbanizador en las tierras más desvinculadas de su control; más aún, el "rey Sabio" culminó de esta forma una parte del programa seguramente iniciado

\footnotetext{
${ }^{3} \mathrm{La}$ "restauración" de la monarquía por García Ramírez en 1135 había quedado marcada por el signo de una ilegitimidad que la Curia romana no dudaba en recordar siempre que podía, y que los reinos vecinos no vacilaban en aprovechar a la menor ocasión. Esta circunstancia, y el sostenimiento de la corona sobre la base de los vínculos de dependencia con la aristocracia y del vasallaje ocasional con Castilla, acarreaban una indiscutible debilidad de origen.

${ }^{4}$ Sobre la renovación conceptual del reinado de Sancho el Sabio, vid. A. J. MARTín DUQUE, Sancho VI y el fuero de Vitoria, "Vitoria en la Edad Media", Vitoria, 1982, pp. 283-295.

'Resulta interesante reslatar que la modernización de los modos de gestión de patrimonio es una preocupación que comparten otros monarcas y señores coetáneos, como el propio Alfonso II de Aragón (1162-1196), (Vid. M. SÁNCHEZ MARTíNEZ, La evolución de la fiscalidad regia en los países de la Corona de Aragón (c. 1280-1356), "Europa en los Umbrales de la Crisis (1250-1350)", "XXI Semana de Estudios Medievales de Estella (1994)", Pamplona, 1995, pp. 395-396.
} 
por el padre ${ }^{\circ}$. Todo el proyecto sirve de respaldo a la nueva intitulación regia que aparece oficialmente a partir de 1162: no se trata ya del rey de los pamploneses, azotado por los avatares del rechazo pontificio y de las fidelidades cambiantes e inesperadas de la poderosa nobleza local, que oscila peligrosamete entre la fidelidad a Castilla y la del rey pamplonés, o mantiene ambas a la vez; se trata del reino de "Navarra", instituyendo claramente una idea de territorialidad que antes faltaba y que, de paso, redefine la esencia de la monarquía. No estaría muy lejos de estos planteamentos el propio Felipe II Augusto, que en 1204 inaugura también el título de rey de Francia"?.

El reino adquiere ahora unos perfiles, en principio, más concretos y definidos, y la soberanía, que reside en el monarca, deberá sustentarse desde entonces en este perímetro territorial, y no en las fidelidades ocasionales que, llegado el caso, pueden debilitarlo o incluso aniquilarlo. Como antes se ha indicado, este planteamiento exige una contrapartida inmediata, que Sancho el Sabio acometió sin vacilar: la potenciación de enclaves de poder regio en los ámbitos más expuestos a los cambios de fidelidad y más vinculados a los poderes señoriales locales: Vitoria y San Sebastián, y el desarrollo de una vasta política de renovación e implantación de cuadros de control del espacio -tenencias- en toda la banda más occidental del reino; aunque a la postre fracasara, se trata sin duda de una poderosa apuesta por la concreción espacial y la acotación soberana. Ese proceso de demarcación territorial y de los resortes del poder provocaría finalmente la desvinculación de toda la franja occidental del reino, donde no cuajó debidamente el nuevo proyecto y que, con la única resistencia de, precisamente, los núcleos urbanos de nueva fundación, se acogió al vasallaje castellano con toda facilidad en 1199-1200.

\footnotetext{
${ }^{6}$ Aunque la nueva intitulación oficial corresponde a Sancho el Sabio, no deben olvidarse posibles ensayos anteriores, de García Ramírez, especialmente en emisiones monetales donde aparece ya un "rex Garsie" y "Navarre" (E. RAMIREZ VAQUERO, Monedas navarras altomedievales, en "Símbolos e imágenes para una historia de Navarra", Pamplona, 1996 (en prensa).

'Eso que algunos autores llaman el paso de un "principe feudal" a un "rey soberano" (O. Guillot, A. Rigaudière, Y. SASSIER, Pouvoirs et Institutions dans la France Médiévale. Des temps féodaux aux temps de l'État, París, 1994, p. 90), tiene seguramente mucho que ver con definiciones de este calibre en la cúspide de la monarquía. El mismo A. Rigaudière califica el reinado de Felipe Augusto como de "tiempo del Estado,...de reconstrucción territorial..." [L'essor de la fiscalité royale du règne de Philippe le Bel (1285-1314) à celui de Philippe VI (1328-1350), "Europa en los Umbrales de la Crisis (1250-1350)", "XXI Semana de Estudios Medivales de Estella (1994)", Pamplona, 1995, p. 324].
} 
Resulta cada vez más evidente, a la vista de la documentación de la época y de las emisiones monetales, que el período que va desde García Ramírez hasta su nieto Sancho el Fuerte debe ser considerado como una etapa unitaria, donde se va desarrollando y poniendo en práctica una vasta propuesta de reconstrucción de la monarquía cuidadosamente desplegada, según las posibilidades y contexto de cada monarca. Cabe considerar, por tanto, que cuando llegan a Navarra las primeras dinastías francesas, el reino presentaba unos perfiles más definidos y compactos que los de medio siglo antes, y había superado la debilidad que rodeaba a la ilegitimidad de los descendientes de García Ramírez. Más importante aún, estaba ya en marcha un intenso proceso de reforzamiento de al menos dos pilares fundamentales del poder: el control del territorio -a través de la renovación de las tenenciasy la racionalización de los ingresos del rey; queda por conocer el estado de un tercer aspecto, la aplicación de la justicia, cuyos resortes hasta entonces debían ser simples y apenas los intuimos más allá de lo que traslucen los textos normativos, o en la existencia de unos pocos organismos en la propia Curia regia. Estas tres cuestiones, en particular las dos primeras, serán centro de atención preferente de las nuevas dinastías, en un largo proceso de más de dos siglos de ajustes de la gestión, encaminados a conseguir un organigrama de gobierno eficaz y una idea del ejercicio del poder más abarcadora.

\section{ChAMPAÑESES Y CAPETOS: \\ LAS BASES DE UNA NUEVA MONARQUÍA}

La monarquía de las primeras dinastías francesas, que en sus lugares de origen contemplan una intensa reestructuración del poder regio, al menos en los dominios directos de la corona, atenderá de forma preferente las tres cuestiones aludidas más arriba. Suele ser relativamente habitual, en estos temas, seguir un planteamiento sectorial, deslindando los tres ámbitos de la presencia regia para una mayor claridad expositiva; sin embargo, dada la profunda imbricación existente entre sí, se ha preferido mantener aquí el sentido unitario, intentando plantear un análisis general del avance de los resortes del poder, en una visión más bien cronológica. 
Para finales del siglo XIII ${ }^{8}$ un nuevo organigrama ha sustituido completamente a las viejas tenencias, claramente inoperantes para la gestión de la monarquía: las merindades constituyen un amplio espacio, centralizado en su cabeza de merindad, donde un funcionario regio, el merino, representa el poder ejecutivo del monarca: atiende su patrimonio y mantiene el orden pœblico 9 . El sistema no recoge, sin embargo la nomenclatura francesa, sino la peninsular, y el término -de hondas raíces en la administración del realengo castellano- estaba presente en la tradición de la realeza pamplonesa por lo menos desde finales del siglo $\mathrm{XI}^{10}$. Ya con unos perfiles más parecidos a los que tendrá en el siglo XIII, consta un merinus regis con García Ramírez, y luęgo con Sancho el Sabio, que A. Martín Duque define como "intendente mayor, técnico en finanzas" "I posteriormente, también Sancho el Fuerte alude a un "merino suyo" en algunas regulaciones de derechos señoriales a principios del siglo XIII ${ }^{12}$. Aunque sea prematuro querer ver un organigrama de merindades del reino para estas fechas, es evidente que el cargo, como delegado señorial del rey en sus tierras, siquiera de forma puntual, ya era efectivo, y posiblemente fue esta una de las razones por las que luego la administración se concretó de esta manera y no de otra.

El modelo francés, en cambio, era algo distinto y estaba también en pleno proceso de maduración; en los dominios de los Capeto, desde fines del siglo XII, son las bailías y senescalías las que constituyen la pieza maestra de la administración territorial ${ }^{13}$, con una carga judicial indiscutible y predominante, ya que la aplicación de la justicia es, precisamente, interés

\footnotetext{
${ }^{8}$ El primer registro de cuentas del reino completo y estructurado, en el que es posible distinguir claramente una serie de espacios administrativos. Pub. J. ZABALO, El registro de Comptos de 1280, Pamplona, 1972. Archivo General de Navarra, Reg. 2. (En lo sucesivo, AGN).

${ }^{9} R$. García Arancón recoge las funciones específicas del merino bajo la dinastía champañesa (Teobaldo II, pp. 125-126).

19M.R. FONT CAÑELLAS, Léxico romance en documentos medievales aragoneses (siglos XIXII), Zaragoza, 1994, S.V. Merino.

"A.J. MaRTín Duque, Fuero de Vitoria, p. 284 y nota 18.

${ }^{12}$ En 1201 y 1203 (L. J. ForTúN, Colección de fueros menores, doc. n. 58 y 60). A este respecto, el propio editor de los documentos, en el estudio correspondiente [Los "Fueros menores" y el realengo en Navarra (siglos XI-XIV). "Príncipe de Viana", 46 (1985), p. 642] describe las funciones del merino según la definición de J. Zabalo para el siglo XIV, perfectamente aplicable.
}

${ }^{13}$ Vid. O. Guillot, A. Rigaudière, Y. Sassier, Pouvoirs et Institutions, pp. 217 ss. 
primordial del monarca ${ }^{14}$. El proyecto de diseñar un sistema de senescalías en Navarra, al parecer el más adecuado para territorios de mayores dificultades de control ${ }^{15}$, no pasaría de ser un breve ensayo en tiempos de Luis Hutín. Se intentó entonces conformar tres grandes circunscripciones (Pamplona, Estella y Tudela), que quizá pretendían quebrar la unidad del reino $^{16}$; en todo caso, y a la luz de lo antes comentado, sí debe ser considerado como un intento de reestructuración del ejercicio del poder, en la línea de dureza que presidió el mandato capeto a partir de los hechos de la Navarrería en $1276^{17}$.

Sin embargo, y aparte de la configuración de merindades antes comentada, y del fracaso del programa de senescales, en Navarra sí se consignan bailías y bailes, que, en cierto sentido, plantean un problema de encuadre interesante, debido a una serie de particularidades que vienen dadas, en buena medida, por la existencia previa de unos cuadros de gestión de la monarquía que no es posible eliminar ${ }^{18}$. La figura del baile aparece con al menos dos planos diferentes en Navarra ${ }^{19}$, de los que al menos el segundo tendría un mayor vigencia y peso administrativo; el primer tipo es similar o comparable a un "submerino", colocado al frente de áreas de diversa consideración -valles, comarcas, villas de realengo, etc.- y responde a una especie de delegado del poder real en la comarca.

\footnotetext{
${ }^{14} \mathrm{La}$ distribución de unas y otras responde, por lo visto, a un criterio, de eficacia de la gestión, distribuyéndose las primeras por las tierras septentrionales -donde predomina el patrimonio directo de la corona-, y las segundas en la parte meridional; esta geografia, lejos de responder a una distribución aleatoria de oficiales iguales con nombre distinto, o a causas de diferente estructura social de unos y otros territorios, coincide con una forma distinta de ejercer el poder real. Vid. H. Takayama, The local administrative system of France under Philip IV (1285-1314), baillis and seneschals, "Journal of Medieval History", 21 (1995), pp. 167-193.

${ }^{15} \mathrm{La}$ mayoría de las senescalías comportaban una estructura interna más compleja, y tenían su origen en antiguas unidades tradicionales, "regiones históricas", diríamos en la actualidad, (H. TAKAYAMA, Local administrative. pp. 176 y 182-185).

${ }^{16} \mathrm{~J}$. Gallego Gallego, Enrique I, Juana I y Felipe I el Hermoso, Luis I el Hutín, Juan I el Póstumo, Felipe II el Largo, Carlos I el Calvo (1270-1328), Pamplona, 1994, pp. 228-231.

${ }^{17}$ No procede aquí hacer balance del áspero enfrentamiento entre la corona y la nobleza local que se saldó con la entrada de las tropas fancesas en la Navarrería, en 1276.

${ }^{18}$ Abundando en el artículo de $\mathrm{H}$. Takayama, las bailías francesas (aparte de las que corresponden a distritos internos de las senescalías), corresponden en su mayor parte a los viejos territorios del patrimonio real, donde el monarca tenía una vinculación más directa, y la función de los bailes se centraba especialmente en las cuestiones judiciales y financieras (pp. 183-184).

${ }^{19}$ Los describe J. ZABALO, Administración, pp. 113-118, aunque él distingue tres clases diferentes.
} 
El segundo tipo, colocado en las cabeceras de las merindades y otras villas francas, pero no supeditados al merino, permite un análisis de gran interés. Se trata de un oficial casi paralelo al merino, que representa y proteje los derechos del rey, ejecuta la justicia y mantiene el orden poblico en su distrito, pero que debe convivir con otros oficiales de vieja raigambre en la tradición del reino, que ya detentaban esas funciones en esos ámbitos y que no desaparecen: almirantes, prebostes, justicias ${ }^{20}$. El reparto de poder se perfila con relativa nitidez enseguida, entre el ámbito señorial y el jurisdiccional: el baile se ceñirá de forma casi exclusiva a la gestión del patrimonio real, es decir, el cobro de rentas; los demás a la aplicación y ejecución de la justicia ${ }^{21}$. Pamplona es un caso paradigmático en este sentido: ciudad de dominio episcopal hasta 1319, los alcaldes de los distintos núcleos ciudadanos son nombrados por la mitra, o a veces por el obispo y el rey, si los acuerdos coyunturales entre ambas partes así lo han estipulado; pero el obispo tiene siempre un almirante propio, representante del señor en la ciudad y del que conocemos al menos el caso de San Cernin ${ }^{22}$. El rey tiene a su vez un baile que gestiona sus derechos patrimoniales y los del mercado, ya incluso en 1266, antes de cualquier conflicto abierto con la mitra ${ }^{23}$.

Bailes y mexinos, o prebostes y sus congéneres, no representan, sin embargo, en Navarra un organigrama judicial como el que se plantea en Francia ${ }^{24}$, pues la administración de la justicia no se origina en sus tribunales, sino en los asentados en los mercados, donde se aplica la norma vigente para cada cual. Les corresponde, eso sí, la aplicación de la ley; de

\footnotetext{
${ }^{20} \mathrm{El}$ término es indistinto, y se refiere al representante del rey en los burgos francos, para la gestión de su patrimonio -y la percepción de las rentas que éste devenga-, la ejecución de la justicia en nombre del monarca -con sus ingresos correspondientes- $y$ la salvaguarda del orden público en ferias y mercados (luego también en la celebración de Cortes del reino). Vid. R. GaRCía, Teobaldo II, pp. 316-319 y J. ZaBALO, La administración, pp. 285-290).

${ }^{21}$ Con una sola excepción, la justicia hebrea, que siempre figura vinculada al baile; no procede aquí detenerse en las causas de esta distinción, relacionadas quizá con el mismo tema de la jurisdicción; más adelante aparacerá un baile de los judíos, que con el tiempo podrá ser el mismo que ostenta el cargo para los cristianos, como es el caso de Pedro Caritat, baile de Tudela, recibidor de las rentas de la bailía y baile de los judíos $(1351$, AGN, reg. $65, f .1$; 1352, reg. 71, f. 26).

22J. GoÑı, Historia de los Obispos de Pamplona (siglos VIII-XIII), Pamplona, 1979, I, pp. $609,658$.

${ }^{23} \mathrm{AGN}$, reg. 1, f. 10.

${ }^{24}$ O. Guillot, A. Rigaudière, Y. Sasier, Pouvoirs, p. 219.
} 
ahí la existencia de una carcel del merino, la consignación del cobro de multas, y la ejecución de las penas. Sus funciones, con todo, recibirán la lógica evolución derivada de una mayor complejidad de la adminstración en el siglo XIV, sobre todo a partir de la mayor presión ejercida por los Capeto. El proceso resulta, en este sentido, de un gran interés, $y$ a él se ha aludido antes con referencia al deslinde de las funciones más directamente patrimoniales -la recaudación de rentas- de las extrictamente jurisdiccionales: la aplicación de la justicia y el mantenimiento del orden público ${ }^{25}$. Desde el segundo decenio del siglo XIV aparece un recibidor o recaudador de la merindad distinto del merino, al tiempo que aparecen igualmente recibidores de las bailías, en este caso no siempre distintos del baile ${ }^{26}$. En este último caso, el proceso resulta además un tanto distinto, pues prebostes, almirantes $y$ justicias ya ejercen las funciones judiciales que antes se han comentado.

Un ámbito de gran interés se sustrae, sin embargo, a estos patrones de gestión, el de las tierras de Ultrapuertos, nunca constituidas en merindad, y mucho más cercanas, en apariencia al menos, a los esquemas aplicados en Francia. Organizadas en al menos tres circunscripciones ${ }^{27}$, San Juan de Pie de Puerto, Mixa-Ostabares y Labastide Clairence, que tienen unos perfiles comparables a los de las bailías, el "castellano" o alcaide de San Juan es con frecuencia su baile; la tierra de Mixa-Ostabares se configura directamente como una bailía, y Labastide, núcleo franco fundado a principios del siglo $\mathrm{XIV}$, tiene también un baile al frente, como delegado real. La falta de un merino como el de los restantes territorios del reino, se suple en determina-

\footnotetext{
${ }^{25}$ Por razones evidentes, no es posible abordar aqui el sugerente tema del gobierno municipal, de las llamadas "buenas villas", por quienes la corona mostró enseguida un especial interés en obtener la mayor rentabilidad posible de su patrimonio y variados derechos. La aportación más reciente y novedosa corresponde a J. CARRASCO, Régimen tributario y organización financiera en las "buenas villas" del reino de Navarra (ss. XIII-XV), "V Congreso Int. de Estudios Medievales". Finanzas y fiscalidad municipal, León, 1995 (en prensa).

201311: Montañas (J. ZABALO, La adminitración, p. 148). Al distinguirse un merino del recibidor de la merindad, el primero se ocupa del orden público y la aplicación de la justicia, y el segundo de la recaudación de rentas patrimoniales; en cierto modo, se traspone a las merindades la distinción ya existente en las bailías. En este caso, además, el protagonismo lo mantiene, precisamente, el recibidor de las rentas de la bailía, mientras que el baile propiamente dicho parece desaparecer en algunas merindades; esas funciones ya las colmaban los prebostes, almirantes y justicias.

${ }^{27}$ S. Herreros Lopetegul, ¿Existió la Sexta merindad?, "I ${ }^{\text {er }}$ Congreso General de Historia de Navarra, 3. Comunicaciones", 1988, pp. 487-489. Corresponde a la misma autora el exhaustivo análisis territorial de las tierras de Ultrapuertos en el Gran Atlas de Navarra. II. Historia, Pamplona, 1986, p. 103.
} 
das circunstancias a través del de Sangüesa ${ }^{28}$, y en ocasiones, y al menos en el primer tercio del siglo XIV, a través de un "procurador del rey" en Ultrapuertos, cuya gestión alcanza a la totalidad del territorio, vinculada a la aplicación de la justicia y a la presencia del poder real ${ }^{29}$.

\section{SISTEMATIZACIÓN FINANCIERA DEL TERRITORIO DE LA MONARQUIÁ}

Resulta lógico considerar que si el establecimiento de una adecuada red de control del territorio era primordial para su aprehensión, esta se traducirá inmediatamente en una mejor y más aficaz percepción de las rentas del patrimonio, que, como se puede observar, constituye una de las funciones principales de merinos y bailes desde el principio. Los propios champañeses mantendrían aquella política de unificación y racionalización de rentas iniciada por Sancho el Sabio, que se plasmaría ahora en una verdadera oficina contable, en el seno de la propia casa del rey. La configuración de una organización financiera acabada, que en cierto modo culmina en 1365 con el nacimiento de la Cámara de Comptos, es, en realidad, una pausada evolución de las funciones de la Curia del rey, de un modo muy similar a lo que había ocurrido en Francia, también desde principios del siglo XIII ${ }^{30}$. Dos chambelanes son los primeros personajes que ejercen funciones financieras centralizadas en época champañesa ${ }^{31}$, si bien no hay constancia expresa de una inspección global de las cuentas del reino $^{32}$, que sin duda se haría ante la propia curia regia, o el gobernador.

\footnotetext{
${ }^{28}$ Que entre otras cosas, se ocupa de las guarniciones de los castillos de Ultrapuertos, función habitual en los diferentes merinos del reino.

${ }^{29}$ Por citar un solo ejemplo, Bernardo Cap de Rey en 1334 (AGN, reg. 34, f. 112).

${ }^{30}$ O. Guillot, A. Rigaudière, Y. Sasier, Pouvoirs, pp. 144-150. El pivote central del gobierno de la monarqu'a, desde finales del siglo XII, se localiza en la propia casa del rey y en su corte, donde residen las funciones gubernativas en todo su sentido.

${ }^{31}$ Creste de Sezanne y Miguel de Undiano, considerados como precedentes del tesorero por R. García Arancón; en 1275 un Undiano sigue siendo chambelán con funciones económicas (J. BALEZTENA, Documentos navarros en los Archivos Nacionales franceses. París, Pamplona, 1978, n. 13).

${ }^{32} \mathrm{Se}$ conservan Registros de Cuentas desde mediados del siglo XIII, con un primer registro casi completo para 1266. Con 13 libros para el resto del siglo XIII, la serie continœa casi sin huecos hasta completar toda la época medieval.
} 
La llegada de los Capeto, precisamente, con un ejercicio del poder mucho $m \neq s$ ajustado, debido en buena parte a otras cuestiones que no vienen al caso ahora, renovará y engrasará estos incipientes organismos, dotándolos de una mayor concreción. Aparecen así, en 1289, Pedro Larreve y Martín García, "recibidores de la renta de Navarra", título siempre equivalente al de tesorero cuando no lleva ningún otro adjetivo, y que pocos años antes, en la década de los 80 , eran simples chambelanes ${ }^{33}$. Al mismo tiempo, es posible observar ya un cierto escalafón en la revisión e inspección de las cuentas: en 1290 el merino rinde cuentas al recibidor del reino, el tesore$\mathrm{ro}^{34}$; y 1304 se indica expresamente que el tesorero revisa las cuentas de merinos y bailes, "en presencia de ellos" para presentarlas luego al gobernador ${ }^{35}$. La existencia de una tesorería central se confirma de manera fehaciente con el primero de los cuadernos del tesorero conservado, de 1304, donde figura en primer lugar el fruto de la inspección sobre los recaudadores, para pasar luego a remitir una serie de asientos que se consideran de su competencia directa: peajes, sacas, escribanías, arriendos diversos, etc. Estas cuentas ya solamente evolucionarán hacia la mayor concreción a lo largo del resto del siglo, mientras se incorporan diversas formas de revisión y rendición de los balances: entre el tesorero y los recibidores, o acompañado el primero por unos oidores de cuentas, cuestiones que veremos desarrollarse con mayor intensidad bajo la dinastía de los Evreux.

Un último aspecto de los Capeto merece ser reseñado todavía, pues representa un paso más en el interés por conocer y controlar el patrimonio, aunque de forma un tanto imprecisa todavía. Desde tiempos de Luis Hutín hay constancia en Navarra de un "procurador del rey", con caracter'sticas similares a las que antes se han comentado para el "procurador en Ultrapuertos". Su vinculación preferente a aspectos relacionados con el ejercicio de la justicia no lo exime de responsabilidades de tipo patrimonial, y su figura merece un cierto detenimiento, pues de alguna manera llegará a convertirse en un importante escalafón del brazo judicial de la monarquía. No se trata,

${ }^{33}$ J. BALEZTENA, Documentos, n. 367, para la mención como tesoreros (en un registro, hasta 1290: AGN, reg. 4, f. 14). Aparecen como chambelanes en J. R. CASTRO, Catálogo del Archivo General de Navarra. Sección Comptos. Documentos, Pamplona, 1952-1964, vol. 1, n. 531, 579. (En lo sucesivo, $C A G N$ ).

${ }^{34} \mathrm{AGN}$, reg. 4 , f. 60 v. De esa primera escala de revisiones se deriva el nombre del cuaderno, o las hojas, que recogen el hecho -cuentas de interreceptores-, es decir, "entre recibidores".

${ }^{35} \mathrm{AGN}$, reg. 8, f. 1 . 
sin embargo, de una instancia jurídica, que escaparía en cierto modo a lo que aquí nos interesa ${ }^{36}$, sino de un oficial destinado a recabar derechos devengados por la justicia, en particular los relacionados con el más alto tribunal del reino, el de la Cort, cuyos sellos custodia ${ }^{37}$.

\section{El ESPLENDOR DE LOS EVREUX}

Una maquinaria tan bien engrasada y ajustada como la dejada por los Capeto, a menudo recordados solamente por sus excesos, permitía a la corona llegar hasta el último rincón del reino a percibir sus derechos señoriales y jurisdiccionales, así como la posibilidad de plantear unas primeras derramas generales, dirigidas a la totalidad del reino y destinadas a necesidades extraordinarias. Ya en el cambio al siglo XIII se habían ensayado algunas cuestaciones extraordinarias, dirigidas sobre todo a los judíos del reino, y consideradas ingresos adicionales a las pechas y tasas habituales ${ }^{38}$, pero la nueva dinastía será pronto capaz de acometer este tipo de acciones a gran escala, que antes sólo se plantearon de forma tangencial $^{39}$.

En cuanto al ejercicio del poder real y a la eficacia de su aparato financiero, sólo sería necesario ya matizar y retocar aspectos puntuales del amplio esquema de gobierno de los predecesores, según el incremento de las necesidades y la mayor complejidad social y política lo fueran requiriendo. El organigrama administrativo y de gestión de la tierra no sufriría ya variaciones sustanciales, así, por ejemplo, el desdoblamiento de algunos delegados del poder, como el merino de las Montañas ${ }^{40}$, en dos oficiales,

\footnotetext{
${ }^{16}$ Como antes se ha indicado, el ejercicio de la justicia ordinaria corresponde a los tribunales del mercado, y de ahi en adelante se procede a una serie de posibles vías de apelación, hasta alcanzar la del Tribunal de la Cort (V. J. ZABALO, Administración. pp. 296-307).

${ }^{37} 1318:$ AGN, reg. 17, f. $63 \mathrm{v}$.

${ }^{38} \mathrm{~F}$. Miranda García, El precio de la fe.

${ }^{39} \mathrm{La}$ concesión de ayudas era un tema no exento, todavía, de reticencias; Felipe y Juana de Evreux apenas las pidieron en dos ocasiones, una en relación con la acuñación de nueva moneda y otra para la dote de su hija María, que había de casar con Pedro IV de Aragón (V. F. Miranda García, Juana II y Felipe III de Evreux, Pamplona, 1994, p. 263).

${ }^{\text {so }}$ Territorio ciertamente conflictivo en lo referente al bandolerismo fronterizo, y sumergido habitualmente en conflictos con linajes vecinos de Guipúzcoa o Alava; constan ya duplicados a mediados de la década de 1340; con indicación expresa de una "zonificación" en 1350 (AGN, reg. 62 , f. $46 \mathrm{r}-\mathrm{v}$ ). Sigue tratándose, por supuesto, de una sola merindad, a cargo de un solo
} 
uno para el sector septentrional de la frontera, y otro para el meridional ${ }^{41}$. Mucho más adelante, ya iniciado el siglo XV, Carlos III fundará una nueva merindad, Olite, recortando el mapa de las circunvecinas; no se trata, sin embargo, de una necesidad de tipo administrativo, sino de un planteamiento más o menos áulico, para dotar a la sede principal y prioritaria de su corte de un rango más digno; la villa ni siquiera constituía una bailía con anterioridad, era simplemente un núcleo franco con un preboste ${ }^{42}$ que representaba los intereses de la corona.

Otros aspectos sí eran urgentes para la monarquía, en particular la antes aludida revisión de las cuentas de la corona, en cuya tarea aparecen ahora numerosos oidores o auditores que acompañan al tesorero en sus funciones, aunque sin configurar un organismo de contornos precisos; se trataría, seguramente, de otros miembros de la curia regia ${ }^{43}$. En este mismo contexto hay que encuadrar la mención en 1349 de una "Cámara de los dineros", que, como en Francia, se halla íntimamente relacionada con la casa u hostal del rey, donde sigue radicando el núcleo de sus finanzas. Hay que pensar que alrededor de esta Cámara se mueven el tesorero, sus clérigos y auditores, y así lo trasluce la noticia de que el año antes mencionado hay una especie de "colegio" de expertos revisando las cuentas de los recibidores y del mismo tesorero: el tesorero, el maestre de la Cámara, un secretario del rey y un técnico -clérigo- ${ }^{\text {th }}$. Resulta interesante reseñar que, ni siquiera cuando se cuente con una Cámara de Cuentas específica, desde 1365, el rey dejará de contar con una oficina interna a cargo de las finanzas, y Carlos III potenciaría, precisamente, este último aspecto.

recibidor de las rentas reales de la misma.

"La fundación de una plaza o bastida en la tierra de Aranaz a principios del siglo XIV, que aglutinara el poblamiento y reorganizara ese territorio abierto -por la geografía favorable- y fronterizo de la Barranca, no fue ajeno, sin duda, a esta situación de amenaza relativa para el órden público de la zona.

${ }^{42}$ En otro contexto, sería posible ofrecer el elenco de todos ellos a lo largo del siglo XIV.

${ }^{43}$ Cabe rastrear, en concreto, miembros del cuerpo de alcaldes y notarios de la Cort, es decir, funcionarios relacionados con el ejercicio y la consignación de las actuaciones judiciales; García Pérez de Aranguren, por ejemplo es un caso de notario de la Curia que aparece con frecuencia revisando cuentas (En 1354, como oidor, -AGN, reg. 75, f. 170 v.- y como notario: f. 75).

${ }^{44} A G N$, reg. 61 ,ff. 82 r-v. y 136. 
La creación de la Cámara de Comptos, en $1365^{45}$ representa, pues, la culminación de un proceso de larga gestación en lo relativo a la gestión financiera; se constituye, además, con carácter de tribunal, con capacidad y autonomía para investigar y dilucidar todo tipo de disputas o reclamaciones relativas al abono de derechos reales. Más aún, ostenta la máxima responsabilidad en el cobro adecuado de esos derechos, es decir, en que no se pierda, olvide $o$ abandone el menor ingreso, bajo ningún concepto, con facultad para exigirlo de manera drástica una vez sentenciado a favor de la Corona. Pero en la fundación de la Cámara no se observan novedades sustanciales respecto a la situaciónn precedente, como no sea el reconocimiento expreso de una facultad jurídica y ejecutiva plena ${ }^{46}$; todo el anterior conglomerado de oficiales destinados a la revisión e inspección de las cuentas se sitúa ahora en un encuadre concreto y bien delimitado. Su existencia, sin embargo, altera en alguna medida el sistema de audición, pues los recibidores, y el tesorero, presentaron ahora sus cuentas directamente a la Cámara ${ }^{47}$.

\section{LOS REAJUSTES DE CARLOS III}

Se ha aludido más arriba a algunas intervenciones, de Carlos III en la estructura de las merindades; sin embargo, interesan aquí algunas otras cuestiones más directamente relacionadas con la maquinaria de la monarquía, todavía susceptible de mayores precisiones. Se habían terminado ya los tiempos de agria conflictividad bélica y diplomática de Carlos II, pero se avecinaban otros de un considerable encarecimiento de la vida cortesana y de desarrollo incesante de una nueva diplomacia, más suntuosa e intensa que la precedente. Las distintas permanencias del monarca en Francia, por otra parte, le permitieron conocer de cerca el sistema engrasado por un monarca esencialmente renovador como había sido Carlos V, su primo, que daría sus

\footnotetext{
${ }^{45}$ Ordenanza en AGN, Comptos, 18, n. 12.

${ }^{46}$ Ejemplo de la capacidad ejecutiva de los oidores antes de la constitución de la Cámara, y por citar uno sólo de los muchos ejemplos, es una revisión realizada en 1349 donde los auditores piden la rectificación de cuentas de 1346 y 1347, denunciando varias corruptelas del baile, que finalmente será ejecutado, y presentando el listado de cantidades recuperadas (AGN, reg. 60, f. 31 v.).

${ }^{47}$ También en esta cuestión cabe señalar una evolución -imposible de repasar aquí con detalle- que pasa por la revisión conjunta de tesorero y oidores, a la del tesorero por los oidores, y finalmente todas las instancias contables por la Cámara de Oidores de Comptos.
} 
frutos en los largos años de reinado de Carlos $\mathrm{VI}^{48}$. La idea central que parece presidir la política del rey Noble se halla íntimamente relacionada con un mayor control sobre las finanzas del reino, en particular a través de organismos más cercanos a la Curia real, como la Cámara de los dineros del rey, o el Recibidor de los cofres del rey. El contexto es evidente: ante un mayor crecimiento de la corte y su entorno suntuario, el rey quiere gestionar más directamente determinadas parcelas económicas, en particular en el capítulo de gastos. Las cuentas de la tesorería, sin grandes cambios en su estructura y cuantía -por encima de las 150.000 lib. de ingresos anuales habitualmente- sufrirán una brusca novedad a partir de entonces; en 1414 hay constancia de un "recibidor de los cofres del rey" que convive con el viejo tesorero. Este ha pasado a presentar ingresos de poco más de 77.000 lib., mientras el otro cobra casi $120.000^{49}$; en años sucesivos, y hasta 1421 , ni siquiera constan las cuentas del tesorero del reino, cuyo cargo no está vacante ${ }^{50}$.

Las vacilaciones en el seno de la propia tesorería, entre una oficina centralizadora de las cuentas del reino, y otra más vinculada a la casa del rey, no se detendrían en el resto del siglo XV. Cabe plantear que la existencia de una Cámara de Comptos como órgano supremo de las finanzas, dejaba sin sentido, de hecho, un oficial como el tesorero, tal y como este se había entendido a lo largo de la mayor parte del siglo XIV; el propio Carlos II ya había mostrado algunas vacilaciones sobre su designación ${ }^{51}$. Con Blanca y Juan II se observa la presencia temporal de un tesorero del reino y otro "de los reyes", siendo este último el realmente operativo, porque gestionaba la fuente de riqueza más importante: las ayudas extraordinarias ${ }^{52}$

El interés de la corona por una gestión eficaz del patrimonio desemboca, por otra parte, en el desdoblamiento de una figura de carácter

\footnotetext{
${ }^{48}$ Sobre las finanzas de Carlos VI y la estructura del gobierno en el tránsito al siglo XV, Vid. M. REY, Le domaine du roi et les finances extraordinaires sous Charles VI, 1388-1413, París, 1965, 2 vols.

${ }^{49} \mathrm{AGN}$, reg. 333 , f. 8 v.; y reg. 332 , ff. 13 v-14.

${ }^{50}$ Vid. E. RAMíREZ VAQUeRo, Navarre Royal Treasury, En 1421 vuelve a aparecer un registro del tesorero, con unos ingresos de poco menos de 60.000 lib. (AGN, reg. 365, f. 30v.).

${ }^{51}$ En el momento de su ascenso al trono el cargo estaba vacante, y así permaneció durante un plazo inexplicablemente largo, residiendo la jefatura de la tesorería en un clérigo de la Curia (V. E. RAMÍREZ VAQUERO, Navarre Royal Treasury).

${ }^{52} \mathrm{~A}$ partir de 1431 , por lo menos hasta 1442 . AGN, regs. 413, 415, 422, 424, 427, 430, $437,451$.
} 
inquisitorial y ejecutivo, hasta entonces unitaria y centrada, más bien, en las cuestiones judiciales, el procurador del rey. Nombrado un procurador patrimonial en 1400, hay que distinguirlo del anterior, designado desde entonces como "procurador fiscal"; el nuevo cargo iba destinado a llenar una labor de pesquisa y recuperación del patrimonio perdido o usurpado, que en rigor se encontraba entre las atribuciones de la Cámara de Comptos, pero que ésta no podía desarrollar adecuadamente. sumergida como estaba en la inspección permanente de unas cuentas cada vez más complejas ${ }^{53}$.

\section{El TRIUNFO DE UNA FISCALIDAD DE ESTADO}

Se han mencionado más arriba los primeros ensayos de percepciones extraordinarias, distintas de la renta patrimonial, rastreadas al menos desde tiempos capetos, si precindimos del monedaje de $1264 / 1265^{54}$. Se ha aludido igualmente a una media de los ingresos de la corona de más de 150.000 lib. anuales durante el reinado de Carlos III; sin embargo, lo realmente significativo de esta última cifra lo constituye el hecho de que, en ella, las rentas de la tierra apenas representan 10.000 lib. En cambio, corresponde el resto de la recaudación a las ayudas extraordinarias y las alcabalas, es decir, a imposiciones directas e indirectas, concedidas por las Cortes del reino y recaudadas según una tasación previa que abarca, al menos en principio, todo el espectro social y, en cualquier caso, todo el abanico campesino -independientemente de su adscripción señorial- y burgués ${ }^{55}$.

Hasta llegar a tales niveles de percepción, el proceso fue evidentemente paulatino; dejando aparte el monedaje del inicio del reinado, y la

\footnotetext{
${ }^{53}$ Sobre el procurador patrimonial y su caracterización a lo largo del siglo $\mathrm{XV}$, Vid. E. RAMíREZ VAQUERO, La Hacienda navarra en el siglo XV. El procurador patrimonial, "Actas del XV Congreso de Historia de la Corona de Aragón", Zaragoza, 1996, pp. 1-17.

${ }^{54} \mathrm{El}$ monedaje constituye, lógicamente, una derrama general y extraordinaria, pero tiene un objetivo muy concreto $y$, en principio, irrepetible durante un reinado. Los primeros ensayos capetos, en cambio, de peticiones a los judíos, pueden ser encuadrados, quizá, en una concepción distinta, más relacionada con lo que luego serán los subsidios sistemáticos.

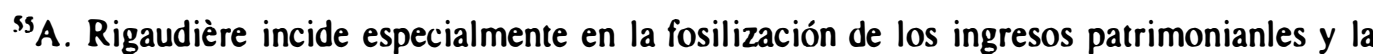
puesta en práctica de otros mecanismos desde finales del siglo XIII ( $L$ 'essor de la fiscalité royale, pp. 323-324).
} 
ayuda concedida por la clerecía por el advenimiento de la corona ${ }^{56}$, es posible rastrear en 1356 la concesión de una ayuda otorgada por hidalgos, infanzones y francos, de las "primicias de sus frutos" de tres años consecutivos, que convive con otra ayuda concedida por las aljamas del reino, adicional a la pecha ${ }^{57}$. hasta llegar a la primera verdadera derrama $(30.000$ lib.) concedida a Carlos II, en 1358, sobre el estamento nobiliario y burgués. precisamente, seguida al año siguiente de otra que grava al mundo campesi$\mathrm{no}^{58}$. Los sucesivos recuentos de fuegos del siglo $\mathrm{XIV}^{59}$ evidencian un interés claro por conocer de la forma más ajustada posible las posibilidades demográficas del reino. La guerra siempre fue, como ya ha sido puesto de manifiesto por otros autores, el motivo ideal para pedir subsidios, $y$ es bien sabido que Carlos II aprovechó eficazmente todas las ocasiones posibles, sin que sea pertinente aquí enumerar todas y cada de ellas. Para Carlos III, en cambio, tal eventualidad había quedado zanjada, pero el rey noble pudo aludir a unas "necesiades del rey" siempre urgentes, aparte de matrimonios, viajes, y demás excusas, para obtener un balance de ingresos del calibre del antes comentado. Para entonces, incluso, la alcabala había modificado sensiblemente su forma de cobro inicial, de impuesto indirecto que grava las compraventas, pues se ha convertido en una cantidad global que se reparte de forma parecida a los cuarteles, y que grava, por tanto, de forma casi directa. En este sentido, cabe observar que ya desde una fecha tan temprana como 1361 los judíos de Monreal tenían sus alcabalas tasadas por fuego, a 14 dineros cada uno ${ }^{61}$.

Para finales del siglo XIV, el triunfo de la fiscalidad de estado es tal que se ha convertido realmente en el sostén indiscutible del reino, que no puede subsistir con unas rentas ordinarias realmente limitadas, por $m \neq s$ que el procurador patrimonial ensaye a lo largo del siglo XV una ingente labor de pesquisa y reconversión de rentas antiguas -pechas- a nuevos modos de explotación más rentables, como censos y arrendamientos ${ }^{61}$. La estimación

\footnotetext{
${ }^{56} \mathrm{AGN}$, reg. 68, f. 144.

${ }^{57} \mathrm{AGN}$, reg. 82, ff. 123 ss. La de los judíos, en reg. 79, f. $18 \mathrm{v}$.

${ }^{58} \mathrm{AGN}$, reg. 86, f. 39 . La de los labradores, reg. 100 , f. 53.

${ }^{59}$ Los publica exhaustivamente, y realiza el consiguiente estudio, J. CARRASCO, La población de Navarra en el siglo XIV. Pamplona. 1973.

${ }^{60}$ AGN, reg. 101, f. 92 . Se contabilizan 14 casas.

${ }^{61}$ Sobre la labor del patrimonial, descrita someramente por J. Zabalo, pues su trabajo se ocupa del siglo XIV, vid. E. Ramírez VAQUero, La Hacienda Real.
} 
de las posibilidades recaudatorias emprendida en 1427 arrojó conclusiones inequívocas ${ }^{62}$ : la corona no podía seguir percibiendo tasas extraordinarias del calibre de las precedentes, porque el reino no estaba en condiciones de abonarlas.

El sistema de control del territorio y de ejercicio del poder, por tanto, esbozado de manera imperfecta desde antes de la llegada de los champañeses, había alcanzado su plenitud en los años centrales del siglo XIV, y contemplará después apenas unos leves retoques. Este organigrama, debidamente engrasado y eficaz ofrecerá seguramente sus máximos frutos con Carlos III en el tránsito al siglo XV; su competencia y la operatividad de sus resortes de gestión serán precisamente lo que permitirá que la maquinaria siga funcionando en un período más bien anodino como el de la reina Blanca y luego su hijo Carlos, hasta el inicio de la guerra civil en 1450. Y será la guerra, precisamente, con la larga quiebra del ejercicio del poder real, hasta final de siglo, lo que lo hará inoperante por primera vez, si bien no en la totalidad de su estructura. Así, se mantendrá vigente todo el aparato administrativo, financiero y judicial del reino, aunque sin una clara orientación política; fallaría, justamente, la autoridad necesaria -porque no la había- para recaudar las rentas de la corona -menguadas, además, por la situación crítica general- e, incluso, para recabar de las Cortes -fragmentadas en dos obediencias distintas- cualquier subsidio extraordinario. Así pues, si el aparato de la gestión administrativa y judicial podía sostenerse aun faltando una autoridad bien centrada, porque estaba bien articulado y no dependía, en último término, de la presencia o no de la corona, otra cosa muy distinta ocurría con las finanzas, que precisaban una titularidad que las solicitara y percibiera.

En ese contexto, la ingente labor que hubieron de enfrentar Juan III y Catalina, y a la que destinaron todos sus esfuerzos una vez que consiguieron ser coronados en Pamplona, diez años después de haber ocupado el trono, sería la de la restauración del poder de la corona; ésta era la única forma para reconstruir el patrimonio, reestructurar unas necesidades y prioridades financieras y rehabilitar los modos de percepción, que, cuando

\footnotetext{
${ }^{62}$ AGN, Libro de Fuegos de 1427/1428, s/sign. Al año siguiente, la tasación de los cuarteles fue rebajada en un $50 \%$, procentaje que se mantendrá durante el resto del siglo, evidenciando la imposibilidad del reino de asumir mayores inversiones [V. E. RAMíREZ VAQUERO, Patrimonio de la corona e ingresos fiscales en Navarra en el siglo XV, "Revista Huarte de San Juan", 2 (1996)].
} 
se ensayaron -infructuosamente- fueron los ya conocidos. La tarea pasaba por someter a los bandos nobiliarios, desbordados desde 1450, pero se concretó en medidas altamente significativas, la confiscación de bienes, en un intento desesperado por incrementar el patrimonio regio y recuperar el respaldo social, elementos imprescindibles para hacer funcionar de nuevo una maquinaria que sólo la nueva situación del siglo XVI pudo desatascar.

\section{RÉSUMÉ}

La Navarre a connu durant le XIII' siècle un intense procéssus de mise à jour et de modernisation des structures du pouvoir royal et de l'état. Cette analyse a pour but d'étudier dans un essai de synthése, l'état de la question, et plus particulièrement les mécanismes de contrôle du territoire, la rationalisation et la systématisation des revenus du patrimoine et l'exercice de la justice. Le point de départ sera donc, la nécessaire plate-forme établie pendant la deuxième moitié du XIr siècle par les derniers descendants directs de la dynastie de Navarre, où se sont fixées les bases du pouvoir souverain pendant le Bas Moyen Age. Au XIV $V^{e}$ siècle la nouvelle monarchie des Champenois, et surtout celle des Capétiens, poursuivront les changements administratifs jusqu'à l'apogée de la fiscalité et des structures d'un état moderne. La faiblesse du pouvoir royal pendant la seconde moitié du $\mathrm{XV}^{\mathrm{e}}$ siècle provoque le début de la faillite d'un système qui réussira pourtant à se reconstruire dans un schéma bien articulé et cohérent pour les temps modernes.

\section{SUMMARY}

Navarre was submerged during the XIIIth century in an intense process of actualization and modernization that changed the organization of the royal power. The objective of the analysis in this article is to give an overview of this evolution, while synthesizing and presenting an account of the state of affairs by focusing mainly on the mechanisms for controlling the land, the reorganization, administration and systematization of the income generated by the king's patrimony, and the exercise of jurisdiction. The study departs from the necessary platform established in the second half of the xilth century by the last monarchs who pertained to the Navarrese dynasty, and created the foundation for a new definition of sovereign power during the Low Middle Ages. The new royalty of the "Champenois" and moreover the Capetians, continued the administrative readjustments during the XIVth century until the fiscal system and the mechanisms of a modern state triumphed. The weakness of royal power during the second half of the XVth century introduced the first breakdown in a system which nevertheless rebuilt itself into a well-articulated structure, consistent for modern times. 